\title{
Educação Física: corpos negros e insurgências epistêmicas
}

\section{Physical Education: black bodies and epistemics insurgences}

\section{Educación Física: cuerpos negros e insurgências espistemicas}

\author{
Ivanilde Guedes de Mattos ${ }^{a, b, c *}$ (D), Pamela Tavares Monteiro ${ }^{d}$ (iD \\ aUniversidade do Estado da Bahia. Salvador, BA, Brasil. \\ 'Universidade Estadual de Feira de Santana. Feira de Santana, BA, Brasil. \\ 'Universidade Estadual de Feira de Santana, Curso de Licenciatura em Educação Física, Grupo de Pesquisa Firmina. Feira de Santana, BA, \\ Brasil. \\ dPrograma de Pós-graduação em Educação Física, Universidade Federal do Espírito Santo. Vitória, ES, Brasil.
}

Palavras-chave:

Corpo negro e

educação física;

Currículo insurgente;

Estéticas afro.

\section{RESUMO}

O presente trabalho se propõe a refletir sobre a construção de um currículo insurgente pautado no ensino das relações étnico-raciais, trazendo aos conteúdos da Educação Física os estudos afrorreferenciados e culturais. Em razão das desigualdades socio-raciais, tais estudos dialogam diretamente com as implicações oriundas dos corpos negros na escola, considerando as estéticas afro-diaspóricas e a filosofia Ubuntu como base para o cumprimento dos conteúdos sugeridos pela Lei no 10.639/03 por meio de uma pedagogia interdisciplinar.

\section{Keywords:}

Blackbody and physical education; Insurgent curriculum; Afro aesthetics.

Palabras-clave: Cuerpo negro y educación física; Currículum insurgente; Estética afro.

\section{ABSTRACT}

This paper proposes a construction of an insurgent curriculum based on the teaching of ethnicracial relations, african referenced and cultural studies to the contents of Physical Education. Such studies directly dialogue with the implications of black bodies at school. Considering the Afro-diasporic aesthetic and the Ubuntu philosophy, the bases for the fulfillment of the contents suggested by Law 10.639/03 through an interdisciplinary pedagogy.

\section{RESUMEN}

Este artículo tiene como objetivo reflexionar sobre la construcción de un currículo insurgente basado en la enseñanza de las relaciones étnico-raciales, acercando los estudios culturales y de referencia a los contenidos de la Educación Física. Los estudios dialogan directamente con las implicaciones de los cuerpos negros en la escuela. A considerar la estética afrodiaspórica y la filosofía Ubuntu como bases para el cumplimiento de los contenidos sugeridos por la Ley $N{ }^{\circ} 10.639 / 03$ con una pedagogía interdisciplinar.

\footnotetext{
*Autor correspondente:

Ivanilde Guedes de Mattos

E-mail: ivyfirmina@gmail.com 


\section{INTRODUÇÃO}

A Educação Física como área de conhecimento vem aos poucos assumindo o debate sobre as ideologias colonialistas que impuseram um olhar nocivo nos corpos negros, entendidos como sujos, brutos, selvagens e não humanos. Torna-se urgente protagonizar autoras que se debrucem sobre essa problemática de forma pertinente e legítima, fortalecendo o compromisso com o campo da Educação Física e o da educação das relações étnicoraciais.

A Educação Física possui um enorme problema com a implementação do ensino das relações étnico-raciais na escola por causa da ausência dessas discussões na formação docente e por conta do racismo institucional escolar (Monteiro e Anjos, 2020). Portanto, é necessário promover novas discussões e políticas para a mudança desse cenário.

No Brasil, o corpo negro é essencialmente o protagonista de um fenômeno que se inscreve na diáspora insurgente e resistente. Esses corpos têm causado um diálogo muito rico em torno de si: seus usos e recursos contra estereótipos, estigmas, violência, objetificação e racismo. São suas estéticas afrodiaspóricas que assumem o campo da luta antirracista. Antes, é preciso descrever o que são as estéticas afrodiaspóricas. São essas novas composições estéticas da juventude negra (crianças, homens, mulheres e LGBTQ+) que ressignificam o uso dos cabelos crespos por meio da utilização de tranças (nagô, coloridas, brox braids, dreadlocks, boxeadoras), cortes estilizados (na régua), mega hair, black power, cacheados, crespos, dredados, carecas e até alisados, acompanhados de outros artefatos da moda, como maquiagens coloridas, iluminadas, bocas destacadas por batons de cores fortes, brincos, colares, pulseiras, alargadores, piercings e muitos anéis.

Também compõem essa estética as roupas, em sua maioria, garimpadas em brechós, recicladas, sobrepostas com calçados e meias, concorrendo a um despojamento do tradicional e apresentando uma moda performática/ criativa de matriz africana, insurgindo-se contra normas, valores e comportamentos hegemônicos anteriormente impostos como padrão socialmente aceito.

Tomadas por esse enfrentamento aos padrões sociais de comportamento, estéticos e de atitudes, iremos aprofundar essa interlocução orientadas pela premissa reconhecida por Desmond Tutu: o Ubuntu. Portanto, tomamos a envergadura desse africano que obteve o Prêmio Nobel da Paz (1984) para ampliar as perspectivas além do que a ordem capitalista e eurocentrada nos condicionou a compreender. Ubuntu é uma filosofia africana praticada por Tutu, especialmente no contexto bastante polêmico do fim do apartheid, quando presidiu a Comissão de Reconciliação e Verdade. Assim:

Ubuntu é a essência do ser humano. Ele fala de como minha humanidade é alcançada e associada a de vocês de modo insolúvel. Essa palavra diz, não como disse Descartes, "Penso, logo existo", mas "Existo porque pertenço". Preciso dos outros seres humanos para ser humano. O ser humano completamente autossuficiente é sub-humano. Posso ser eu só porque você é completamente você. Eu existo porque nós somos, pois somos feitos para a condição de estarmos juntos, para a família [...] somos criados para uma rede delicada de relacionamentos, de interdependência com os nossos companheiros seres humanos, com o restante da criação. (Tutu, 2012, p. 42).

As razões que nos levam a buscar os estudos africanos têm nos aproximado de correntes teóricas que pautam a descolonização do conhecimento. Por meio das encruzilhadas epistemológicas, visamos adotar uma metodologia que abarque as realidades no tempo presente em que as crianças e as juventudes negras estejam imersas.

Destacamos aspectos de natureza formativa, como a valorização do passado histórico, a crítica ao racismo - "[...] preconceito em relação à ascendência étnica combinado com ação discriminatória" (Bethencourt, 2015, p. 21) -, a discriminação e a elevação da autoestima e da autoimagem. Essas formas expressivas da cultura, uma vez consideradas nas construções curriculares, podem contribuir para uma inclusão mais substantiva dos jovens negros e pobres nas escolas, sobretudo nas escolas públicas.

Em outras palavras, partimos do pressuposto de que a análise das presenças e ausências de determinados elementos raciais na estrutura curricular das escolas contribui em grande medida para a identificação e a avaliação das perspectivas inclusivas ou exclusivas nela presentes, trazendo implicações significativas não só para a própria formação dos estudantes, mas também na sua maior ou menor integração à própria escola. Reconhecemos

[...] que o foco do currículo deveria ser no que ele denomina de "differing differences" (diferenciando as diferenças), ou seja: um processo constante de tradução cultural, que possibilita que educadores e pesquisadores em educação possam compreender a relevância do confronto de perspectivas culturais de grupos plurais, incorporando, no currículo, múltiplas versões das identidades presentes nos espaços educacionais, incluindo saberes de grupos étnicoraciais plurais. (Miller, 2019 apud Ivenicki, 2020, p. 38).

Nessa perspectiva, sugere-se que o currículo seja pensado como um terceiro espaço de enunciação, defendendo que ele propicie a exposição a uma alteridade radical que não pode ser prevista, antecipada ou regulada (Bhabha, 1998).

Dessa forma, compreendemos o currículo como

[...] um dos locais privilegiados onde se entrecruzam saber e poder, representação e domínio, discurso e regulação. É também no currículo que se condensam 
relações de poder que são cruciais para o processo de formação de subjetividades sociais. Em suma, currículo, poder e identidades sociais estão mutuamente implicados. O currículo corporifica relações sociais. (Silva, 1996, p. 23).

Ademais, consideramos a multiplicidade de aspectos, normas, procedimentos e práticas que envolvem o processo formativo. Avaliar os currículos hoje e dimensionar as possibilidades de sucesso educacional a partir da forma como eles são construídos implica ir além da dimensão pedagógica. Dar significado e importância aos conteúdos históricos concretos invisibilizados pelas memórias dominantes, à positivação de práticas não codificáveis pelas linguagens convencionais, às sociabilidades não hegemônicas e às múltiplas temporalidades do viver cotidiano pode aproximar os currículos da realidade dos grupos populacionais, historicamente subalternizados, público majoritário nas escolas públicas. Cabe observar que sociabilidade deve ser observada por meio de uma emergência da multidão, na qual os indivíduos compartilham ações baseadas no instante em que vivem e nas condições semelhantes em que se encontram (Bauman, 2005). Acreditamos que isso defina o que ora estamos denominando por currículo insurgente.

Resultante de um esforço coletivo, a educação passa a vislumbrar passos largos em direção a uma educação intercultural. Temos, desde o ano de 2003, mais uma inter-relação que se destaca pela obrigatoriedade de conteúdos:

\section{Lei no 10.639, de 9 de janeiro de 2003}

Altera a Lei no 9.394, de 20 de dezembro de 1996, que estabelece as diretrizes e bases da educação nacional, para incluir no currículo oficial da Rede de Ensino a obrigatoriedade da temática "História e Cultura AfroBrasileira", e dá outras providências.

Art. 1으 A Lei no 9.394, de 20 de dezembro de 1996, passa a vigorar acrescida dos seguintes arts. 26-A, 79-A e 79-B:

Art. 26-A. Nos estabelecimentos de ensino fundamental e médio, oficiais e particulares, torna-se obrigatório o ensino sobre História e Cultura Afro-Brasileira.

$\S 1$ ㅇ O conteúdo programático a que se refere o caput deste artigo incluirá o estudo da História da África e dos Africanos, a luta dos negros no Brasil, a cultura negra brasileira e o negro na formação da sociedade nacional, resgatando a contribuição do povo negro nas áreas social, econômica e política pertinentes à História do Brasil.

$\S 2$ 2 Os conteúdos referentes à História e Cultura Afro-Brasileira serão ministrados no âmbito de todo o currículo escolar, em especial nas áreas de Educação
Artística e de Literatura e História Brasileiras. (Brasil, 2003).

Para tratar de um tema cuja complexidade está posta a partir da necessidade de implementação da referida lei, que tornou obrigatório o ensino da história e da cultura africana e afro-brasileira na educação básica, recorremos ao panorama do lugar dos corpos negros nas construções de currículo no Brasil, em que a presença da cultura africana e afro-brasileira se destaca e faz emergir alguns dos principais conceitos a serem analisados, contribuindo para uma reflexão mais próxima do presente social e cultural em que vivemos e que se constitui pela educação.

A Lei $n$ o 10.639/03 deve assegurar que a escola contemple uma cultura anteriormente concebida como inferior e, portanto, desnecessária como conhecimento formativo, tornando invisível a riqueza cultural particular do continente africano e de seus povos: as lutas e vitórias que contam os seus griôs - guardiões dessa história ${ }^{1}$; as formas de agrupamentos sociais, de economia e sustentabilidade; as formas de elaboração dos planos de liberdade; os mitos que envolvem divindades; os cultos de devoção à natureza; as habilidades artísticas e seus principais monumentos até então desconhecidos pela história; a cultura musical com a magnitude de ritmos e melodias que se fazem presentes em tantas composições e arranjos internacionais, mas que sequer são citadas; e muitas outras histórias que envolvem o continente africano, como a história de tantas Nzingas Comodes, Dandaras, Rainhas Amedas, Rainhas Makedas e Zacimbas Gabas.

\section{OS CURRÍCULOS TRADICIONAIS E A AUS- ÊNCIA DOS CORPOS NEGROS}

Aponta-se que, com o fim da escravização no Brasil, o Estado se viu incapaz de frear a circulação dos negros libertos pelas cidades e impôs medidas severas de controle às populações negras, coagindo, sob efeito de penalidade e reclusão, aqueles que se agrupassem na rua em rodas de capoeira, sambas e candomblés (Mattos, 2013a; Costa, 1989). Tais agrupamentos tinham conotações de organizações negras perigosas, portanto a polícia tinha o dever de inibir essas ações com doses excessivas de violência que atingiam homens, mulheres e crianças. Marcas desse passado se fazem presentes, impressas pelo racismo, sendo necessário haver outras estratégias para não se sucumbir à dor física e da alma.

Nesse cenário observa-se o "não-lugar" do negro: o mundo da arte e da musicalidade acaba por ser o espaço social que melhor se ajusta às potencialidades negras, propiciando um mercado de vendas, trocas e

1 Histórias como a epopeia de Sundiata - rei dos reis que nasceu com sérios problemas e acabou por se tornar imperador do Mali. 
subsistência. Não que esse não seja um bom lugar; mas esse não deveria ser o único lugar para as populações negras [...]. (Mattos, 2013a, p. 160-161).

Durante décadas não se questionaram os conteúdos da história do continente africano transmitidos na escola, sua forma e seus métodos. Consequentemente, gerações incontáveis de atores participaram de uma política de dominação e silenciamento. Assim, "[...] desnaturalizar e historicizar o currículo existente é um passo importante na tarefa política de estabelecer objetivos alternativos e arranjos curriculares que sejam transgressivos da ordem curricular existente" (Moreira e Silva, 1999, p. 31).

O currículo como forma de poder é o lócus determinante para as práticas de exclusão dos conteúdos que tratam das populações minoritárias, havendo uma redução e certo esvaziamento discursivo. "É central a essa tarefa de investigação do currículo oficial uma perspectiva que tenha um foco histórico" (Moreira e Silva, 1999, p. 31). Colabora com esse pensamento:

Em termos das dimensões focalizadas nas experiências curriculares, uma delas refere-se às formas pelas quais as identidades coletivas plurais são trazidas, seja por meio de suas narrativas e estratégias de resiliência empoderamento, e/ou pela articulação dessa dimensão à própria produção de conhecimento em áreas educacionais e pedagógicas (incluindo temas e estratégias de aprendizagem a serem desenvolvidas). (Ivenicki, 2020, p. 5).

Os currículos adotados na sociedade brasileira, por excelência de matriz europeia, buscaram idealizar um modelo de sociedade que cultivasse os padrões e comportamentos europeus, em que crianças e jovens, negros e negras, tiveram sua liberdade castrada em nome de um projeto civilizatório. Ao se referir aos negros, esse espaço denominado "Escola", ambiente privilegiado de "formação" dos indivíduos, discriminou-os e excluiu-os, ora pelo trato ao subjugá-los como inferiores, de forma desumana, ora pela adoção de conteúdos que valorizavam unicamente a cultura branca.

Assim, no que concerne ao processo civilizatório, tivemos dois polos distintos segregando e hierarquizando brancos dos negros: o branco como colonizador e o negro como colonizado, tanto na escravização como na pós-abolição. Desse modo, construiu-se um pensamento hegemônico que norteou as concepções curriculares em nosso país; um currículo excludente que desvaloriza as contribuições dos signos e linguagens oriundas da cultura africana, própria dos corpos afrodescendentes no Brasil.

Consequentemente, "[...] isso transforma a tarefa de teorização curricular crítica em um esforço contínuo de identificação e análise das relações de poder envolvidas na educação e no currículo" (Moreira e Silva, 1999, p. 30). Ter essa noção envolve reconhecer que é a partir de uma (re)construção desse molde curricular, cristalizado e hegemônico, que se aplica a necessidade de reconfiguração desse currículo com base em novas diretrizes curriculares, a exemplo das Diretrizes Curriculares para a Educação das Relações Étnico-Raciais (Brasil, 2013), que implicam as seguintes orientações:

A relevância do estudo de temas decorrentes da história e cultura afro-brasileira e africana não se restringe à população negra, ao contrário dizem respeito a todos os brasileiros, uma vez que devem educar-se enquanto cidadãos atuantes no seio de uma sociedade multicultural e pluriétnica, capazes de construir uma nação democrática. (Brasil, 2013).

Portanto, a Lei no $10.639 / 03$ e as Diretrizes são medidas que deveriam estar sendo cumpridas na educação básica da rede pública de ensino. Assim, vemos como oportuno o contexto educacional desenvolver ações que envolvam a comunidade escolar e não escolar para a diminuição do racismo, o enfretamento das diferentes situações que causam prejuízos às relações entre negros e brancos, e o reconhecimento das diferentes linguagens escolares subjacentes, dando espaço às culturas urbanas e locais que têm a escola como lugar de significação.

Uma das obras clássicas que discutem conteúdos curriculares e formativos é Superando o Racismo na Escola, organizada pelo professor Kabengele Munanga com o objetivo de contribuir para um currículo menos hegemônico e mais diverso. Tal obra explicita o currículo tradicional, asilado da cultura e corporeidade negra, como contribuinte para a evasão escolar e para uma elevada taxa de analfabetismo de crianças e jovens negros:

Não precisamos ser profetas para compreender que o preconceito incutido na cabeça do professor e sua incapacidade em lidar profissionalmente com a diversidade, somando-se ao conteúdo preconceituoso dos livros e materiais didáticos e às relações preconceituosas entre alunos de diferentes ascendências étnico-raciais, sociais e outras, desestimulam o aluno negro e prejudicam seu aprendizado. O que explica o coeficiente de repetência e evasão escolar altamente elevado do alunado negro, comparativamente ao do alunado branco. (Munanga, 2005, p. 16).

Ainda sobre documentos legais que normalizam os conteúdos escolares, temos ainda as Diretrizes Curriculares Nacionais e os Parâmetros Curriculares Nacionais, que precisam ser referenciados como importantes instrumentos na articulação das novas propostas de lei. Desse modo, fazemos uso da seguinte orientação:

Para obter êxito, a escola e seus professores não podem improvisar. Têm que desfazer mentalidade racista e discriminadora secular, superando o etnocentrismo europeu, reestruturando relações étnico-raciais e sociais, desalienando processos pedagógicos. Isso não pode ficar reduzido a palavras e raciocínios desvinculados da experiência de ser inferiorizados vivida pelos negros, tampouco das baixas classificações 
que lhe são atribuídas nas escalas de desigualdades sociais, econômicas, educativas e políticas. (Brasil, 2013).

Elaboramos, portanto, com mais consistência, um caminho estratégico para propor um currículo que compreenda a realidade social e cultural desses que também são espaços de identidade majoritariamente negra e contribuir para que os estudantes se sintam estimulados a expressar sentimentos de pertença.

Essa escolha não é fortuita; são os resultados de trajetórias acadêmicas que permitem, por meio de experiências particulares no campo profissional, identificar a necessidade de investir em um outro modelo de educação formativa que possa contemplar novas abordagens teórico-metodológicas capazes de recriar o ambiente escolar a partir de novos formatos de aprendizagens, que envolvam os estudantes em uma atmosfera lúdica e afirmativa, representativa do seu cotidiano, interativa do ponto de vista do conhecimento e das novas tecnologias, incluindo as práticas esportivas e corporais.

Dessa forma, compreendemos que o contexto educacional atual deve ser auxiliado nos materiais didáticos e por recursos audiovisuais e performáticos. Aproximar o universo escolar proposto da realidade efetiva em que vivem seus atores principais é abrir janelas para a criatividade, interesse, movimento e dinâmicas relacionais entre educadores e educandos, sem falar nas várias possibilidades que essas aberturas estabelecem com o melhor convívio entre a escola e a comunidade ao conceberem um interesse mútuo.

A escola que se predispõe às inovações educacionais aponta para um entendimento renovado, além da inclusão de novas tecnologias e recursos materiais, e promove práticas educativas para os estudantes regularmente matriculados e a comunidade.

Embasada por Ubuntu, é esta escola que pretendemos: um espaço cuja concepção integre a cultura, currículo, família, comunidade, gestores, professores, funcionários e todos os excluídos da terra², tangenciados por uma pedagogia interdisciplinar/ intercultural. Considerando que somos professoras negras atuantes concentradas no campo da Educação Física, temos buscado, a partir da interdisciplinaridade, desenvolver uma linha de trabalho pedagógico que se relacione com outras disciplinas curriculares, a título de contribuir umas com as outras, convergindo, complementando e expandindo o conhecimento para que o aluno perceba a integração dos conteúdos em uma perspectiva menos linear e mais criativa. É uma prática intercultural na medida em que temos nos posicionado acerca da inclusão da diversidade de corpos, suas memórias, histórias e pertencimentos, sejam eles

2 Definição de Franz Fanon retirada do livro Os Condenados da Terra (2006) para designar todos os sujeitos historicamente excluídos. os povos indígenas, quilombolas, ciganos ou asiáticos, ocasionando, assim, tensões para que o currículo e as políticas educacionais revejam seus modelos universalizantes que silenciam identidades e reforçam as desigualdades.

Ao direcionar os conteúdos das práticas corporais da Educação Física para pensar na educação das relações étnico-raciais, recorremos à interculturalidade como pedagogia promotora da descolonização do conhecimento, ou seja, queremos afirmar que tanto o encontro quanto o confronto entre culturas são necessários para a reelaboração de outras metodologias para o ensino e a aprendizagem. A educação intercultural "[...] ultrapassa a perspectiva multicultural, à medida que não só reconhece o valor intrínseco de cada cultura e defende o respeito recíproco entre diferentes grupos identitários" (Fleuri, 2003, p. 73).

Essa proposição, de certo modo, alcança não apenas os grupos étnicos discriminados. O diálogo entre culturas propõe que haja conhecimento, respeito, afeto e necessidade de reconhecer o outro como parte desse universo. Assim, "[...] soluções tanto de caráter epistemológico quanto pedagógico dependem dos envolvidos" (Fensterseifer, 2009, p. 212). O conhecimento científico é cercado de motivações e interesses, sendo necessário nos libertarmos das inibições ontológicas do conceito de verdade. Dessa forma, a educação intercultural propõe rompimentos hierárquicos para o campo da Educação Física.

Os estudos culturais também contribuíram substancialmente para a crítica ao currículo, definindo para a cultura um lugar de destaque no currículo oficial de educação. Não há cultura sem um povo, e o lugar dessas culturas, nesse contexto, deve ser a escola. Os estudos culturais promovem a crítica necessária ao currículo, desestabilizando o que antes era definido como padrão de educação e propondo outro olhar para a cultura popular. Portanto, a partir da crítica aos conteúdos hegemônicos que postularam os currículos de educação, os teóricos da pedagogia crítica abrem outras janelas para o conhecimento, respeitando a diversidade e promovendo a equidade.

Seguindo essa linha teórica costurada com os estudos africanos, reconhecer a cultura negra, seus atores e suas manifestações como conteúdo curricular consiste em conflitar com as barreiras que permeiam o pensamento intelectual - racionalismos e conservadorismos que normalmente são tomados como parâmetros curriculares da educação. Diante disso, afirmamos a cultura negra como forma de produção de conhecimento, tradutora da realidade formativa daqueles excluídos dos processos civilizatórios eurocêntricos. Nesse sentido, envidamos esforços para outras leituras sobre o corpo negro e a educação, considerando a escola como o espaço para a reflexão prática/pedagógica e de compromisso com o debate sobre gênero, raça e educação. Destaca-se a lacuna no campo das produções científicas sobre a 
Educação Física e as relações étnico-raciais, limitação essa que nos faz recorrer a outras áreas de conhecimento para elaboração e construção de propostas pedagógicas descolonizadas. Na obra Estética Afirmativa: Corpo Negro e Educação Física, encontra-se inspiração para desconstruir verdades postuladas sobre o corpo negro e provocar um outro olhar sobre essa corporeidade na Educação Física escolar (Mattos, 2009).

Nessa lógica, contabilizamos, no presente da diáspora africana no Brasil, uma infinidade de prejuízos de ordem moral, social, econômica e cultural, oriundos e consequentes da experiência colonial. O racismo estrutural, presente na sociedade brasileira, constrói instituições e entidades capazes de disseminar a teoria das raças pelos imaginários sociais (Almeida, 2018). Se manifestados com ações discriminatórias, transformam-se em racismos individuais. É importante destacar que, para o mesmo autor, o racismo é inerente à colonização e à sua sucessora, a modernidade.

No Brasil, a discriminação racial é a condição danosa, certamente a mais cruel, dadas as sutilezas de suas práticas. As perspectivas pós-coloniais emergem o testemunho dos países com experiências coloniais e dos discursos dos grupos colonizados. Assim, tais perspectivas "[...] intervêm naqueles discursos ideológicos de modernidade que tentam dar uma normalidade hegemônica ao desenvolvimento e as histórias diferenciadas de nações, raças, comunidades, povos" (Bhabha, 1998, p. 239).

Estaríamos sujeitos ao desconhecimento das ideologias responsáveis por tais condições, se não fossem as lutas travadas entre colonizados e colonizadores, se não tivesse sido derramado tanto sangue e vitimadas tantas vidas em nome da liberdade que hoje temos, inclusive com a oportunidade de sabê-la e reinterpretá-la sob a ótica dos estudos culturais e africanos, que contribuem para desvelar a história e cultura africana. Desse modo, "[...] está claro que estas concepções e inovações temáticas e teórico-metodológicas cumpriram um papel decisivo, no sentido de nos orientar a pensar a escravização e os próprios escravos para além de sua mera posição na estrutura produtiva" (Mattos, 2013b, p. 233).

Assegura que a pedagogia é mais que uma simples transmissão do conhecimento recebido: "[...] ela pressupõe que os estudantes sejam movidos por suas paixões e motivados, em parte, pelos investimentos afetivos que trazem para o processo de aprendizagem" (Bhabha, 1998 apud Giroux, 2003, p. 114).

Ora, se estamos tratando de currículo escolar, estamos pensando como, pedagogicamente, a Educação Física e a musicalidade negra podem ser tematizadas, ou seja, o que da área de Educação Física e dessa dimensão da cultura negra a colonização não ceifou, porque os negros escravizados trouxeram suas músicas por meio da memória acústica, lugar que o açoite não alcançou, portanto é sem dúvida uma ferramenta importante que pode ser refletida nos processos de escolarização. Atrelar a música aos conteúdos da Educação Física é aqui uma proposta híbrida/interdisciplinar e intercultural de duas áreas de conhecimentos capazes de proporcionar ensino e aprendizagem como objetivo principal.

Assim, além de prazeroso para uma parcela significativa dos educandos, essa prática não desconsidera a complexidade de prováveis reações contraditórias acerca da inserção de estratégias pedagógicas descolonizadas que colocam em pé de igualdade conhecimentos das culturas subalternas. Certamente, pode ser também um meio para desencadear o debate e a reflexão sobre diferentes temas - alguns de difícil abordagem didática por parte dos professores, como a homofobia, o machismo, o uso das drogas e o próprio racismo.

\section{CONSIDERAÇÕES FINAIS}

Assim, é oportuna a contribuição dos estudos culturais e africanos, cujas propostas teóricas ampliam as dimensões sobre o currículo, objetivando a desconstrução das bases em que ele foi alicerçado. Em tempos de transformações sociais, deslocamentos de identidades e inovação tecnológica, dentre outros fenômenos da contemporaneidade, essas perspectivas teóricas convidam formadores e intelectuais a um novo desafio: promover a história e a cultura africana e afro-brasileira a um patamar privilegiado na educação no Brasil.

O objetivo primordial das intervenções dos estudos culturais e dos estudos africanos é que se compreenda que as ascendências étnicas combinadas com as ações discriminatórias existem e se transformam. Ao longo do tempo, são criadas novas formas de segregar e discriminar, exigindo reinvenções dos corpos negros.

A Educação Física é a única área que tem o corpo como elemento direto de intervenção (Sales e Almeida, 2015). Assim, ao tratarmos sobre os esportes, temos os jogos Preto x Branco (Abrahão e Soares, 2017), a obra clássica O Negro no Futebol Brasileiro, de Rodrigues (1964), e os inúmeros documentários sobre Martha e o lugar das mulheres (negras e não negras) no futebol. No atletismo, basquete e vôlei, os conteúdos são extensos. As intervenções sobre danças e lutas são repertórios para os estudos culturais, pois é aqui que a corporeidade negra recebe uma maior atenção. Além dos conteúdos propriamente ditos, é preciso que se discutam as origens dos preconceitos e alguns estereótipos, como: o negro possui, de forma inerente, uma ginga ao jogar e ao dançar; o corpo negro é mais resistente fisicamente; e o corpo negro é mais expressivo e/ou ideal para atividades braçais (Staudt et al., 2018).

Portanto, ainda é um enorme desafio à Educação Física que se abandonem os estereótipos disseminados na obra Casa Grande e Senzala, de Gilberto Freyre (1998), e que são reforçados a todo momento na atualidade com elementos de desumanização e exoticidade do corpo negro. É papel das professoras e professores negros, negras, brancas e brancos desvincular, de forma positiva e explícita, as motivações do racismo no Brasil, porém para isso não é suficiente boa vontade; é preciso uma imersão nos estudos práticos e teóricos que abarquem os conteúdos sobre a história e cultura negra. 
Concluímos esta reflexão com a proposição de um currículo insurgente. Outras epistemes surgem à luz da inter-relação dos estudos culturais e africanos e das pedagogias interdisciplinar e intercultural que acontecem nesse contexto de proposição para uma educação das relações étnico-raciais, que garantam a obrigatoriedade dos conteúdos da história e cultura africana e afrobrasileira (Lei no 10.639/03). Ser descolonial é apostar em novas formas de se fazer política e se identificar como parte, reconhecendo que podemos, juntos, fazer emergir uma nova conjuntura social e de disposição ao enfrentamento às opressões, para alcançar "espaços anteriormente inabitados" às populações que estão à margem da sociedade.

Portanto, adotamos esses aportes teóricometodológicos como desconstrutores de uma educação que desconsiderou, entre outros, o significado das culturas africanas. $\mathrm{O}$ objetivo mais importante seguramente das nossas opções teóricas é que a educação precisa hibridizar, descolonizar e escolher percursos que possam apreender as literaturas do ocidente, da Europa e do continente africano, desde que transitem em uma esfera educativa sem hierarquias. Por isso, propomos o diálogo com educadoras e educadores para que possamos colaborar com a criação de um currículo insurgente representativo e contemplador de grande parte da população que não enxerga sua história contada pelos livros didáticos de forma positiva e, especialmente, pelos manuais da Educação Física, que basicamente nunca ofereceram ao corpo negro um lugar em sua história no Brasil. Vale ressaltar que a educação antirracista é função de/para todas e todos, de todas as cores, raças e etnias.

\section{FINANCIAMENTO}

O presente trabalho não contou com o apoio financeiro de nenhuma natureza para sua realização. Ademais, os autores declaram não haver conflitos de interesse.

\section{CONFLITOS DE INTERESSE} interesse.

Os autores declaram não haver conflitos de

\section{REFERÊNCIAS}

Abrahão BOL, Soares AJG. Futebol, raça e identidade nacional: uma análise do desempenho dos jogadores nos jogos preto x branco. Rev Bras Ciênc Esporte. 2017;39(2):183-190. http://dx.doi.org/10.1016/j.rbce.2015.10.002.

Almeida SL. O que é racismo estrutural? Belo Horizonte: Letramento; 2018.

Bauman Z. Identidade: entrevista a Benedetto Vecchi. Rio de Janeiro: J. Zahar; 2005.

Bethencourt F. Racismos: das cruzadas ao século XX. Lisboa: Temas \& Debates/Círculo de Leitores; 2015.

Bhabha HK. O local da cultura. Tradução Myriam Ávila, Eliana Lourenço de Lima Reis e Gláucia Gonçalves. Belo Horizonte: UFMG; 1998.
Brasil. Lei de $n^{\circ}$ 10.639, 2003, de 9 de janeiro de 2003. Altera a Lei $n$ o 9. 394, de 20 de dezembro de 1996. Diário Oficial da União; Brasília; 10 jan. 2003.

Brasil. Ministério da Educação. Secretária de Educação Básica. Secretária de Educação Continuada, Alfabetização Profissional e Tecnológica. Conselho Nacional da Educação. Câmara Nacional de Educação Básica. Diretrizes Curriculares Nacionais para a Educação das Relações Étnico- Raciais e para o Ensino da História e Cultura Africana e Afro-Brasileira. Brasília: MEC; 2013.

Costa JF. Ordem médica e norma familiar. 3. ed. Rio de Janeiro: Editora Graal; 1989.

Fensterseifer PE. Epistemologia e prática pedagógica. Rev Bras Ciênc Esporte. 2009;30:203-14.

Fleuri RM. Educação intercultural: mediações necessárias. Rio de Janeiro: DP\&A; 2003.

Freyre G. Casa-grande \& senzala. Rio de Janeiro: Editora Record; 1998.

Giroux H. Atos impuros: a prática política dos estudos culturais. Tradução Ronaldo Cataldo Costa. Porto Alegre: Artmed; 2003.

Ivenicki A. Perspectivas multiculturais para o currículo de formação docente antirracista. Rev ABPN, 2020; 12(32):3045. http://dx.doi.org/10.31418/2177-2770.2020.v12.n.32. p30-45.

Mattos IG. Estética afirmativa: corpo negro e ensino da educação física. Salvador: EDUNEB; 2009.

Mattos IG. É pra descer quebrando: o pagode e suas performances para a Educação das Relações Etnicorraciais no currículo escolar [tese]. Salvador: Universidade do Estado da Bahia; 2013a. p. 160-161.

Mattos WR. Negros contra ordem. Salvador: Editora Eduneb; 2013b.

Monteiro PT, Anjos JL. A Educação Física e a identidade étnicoracial: o estado da arte nas revistas brasileiras de Educação Física. Motrivivência. 2020;32(61):1-20. http://dx.doi. org/10.5007/2175-8042.2020e62154.

Moreira AFB, Silva TT. Currículo, cultura e sociedade. Tradução Maria Aparecida Baptista. 3. ed. São Paulo: Cortez; 1999.

Munanga K. Superando o Racismo na escola. 2. ed. revisada. Brasília: Ministério da Educação, Secretaria de Educação Continuada, Alfabetização e Diversidade; 2005.

Rodrigues M Fo. O negro no futebol brasileiro. 2. ed. Rio de Janeiro: Civilização Brasileira; 1964.

Sales LV, Almeida NFP. Diversidade racial e educação física escolar na Revista Brasileira de Ciências do Esporte (1979-2013). Conexões. 2015;13(1):129-61. http://dx.doi. org/10.20396/conex.v13i1.2153.

Silva TT. Identidades terminais: as transformações na política da pedagogia e na pedagogia da política. Petrópolis: Vozes; 1996.

Staudt JL, Silva ALS, Magalhães ML. Aptos aos trabalhos braçais, suscetíveis aos vícios morais: representações do homem negro na Revista Educação Physica (19391944). Rev Movimento. 2018;24(2):483-94. http://dx.doi. org/10.22456/1982-8918.73848.

Tutu D. Deus não é cristão e outras provocações. Tradução L. Jenkino. Rio de Janeiro: Thomas Nelson Brasil; 2012. 